\title{
A change in birth mark
}

\author{
Hadi Mirfazaelian • Ahmad Mosalei • \\ Yahya Daneshbod
}

Received: 26 December 2012/ Accepted: 23 January 2013/Published online: 9 February 2013

(C) SIMI 2013

A 29-year-old man presented with change in his truncal "birthmark". He had a giant coat-like, well-defined, cobble stone, hairy congenital melanocytic nevus occupying the whole chest, upper abdomen, left arm, and neck with multiple satellite nevi scattered on other parts of body (Fig. 1a, b). The lesion and several nodules all over the nevus were present with no significant alteration from childhood until the week before, when he had noticed a change in consistency and color of a tiny focus of the main part of the nevus on his left hemithorax. The general physical examination was normal including skeletal examination. Biopsy of the focus was done that showed benign congenital nevomelanocytic proliferation with deep malignant melanoma transformation. On further investigation, there was a nodule in the lung. A biopsy from the lung lesion was performed that revealed metastatic melanoma. The patient was referred to the medical oncology unit for treatment.

Giant congenital nevi (GCN) are often defined as nevi that are greater than $20 \mathrm{~cm}$ in the greatest dimension [1], or nevi that occupy $30 \%$ or more of the body surface area

H. Mirfazaelian $(\bowtie)$

Department of Emergency Medicine, Tehran University of Medical Sciences, Tehran, Iran

e-mail: H-mirfazaelian@razi.tums.ac.ir

\section{A. Mosalei}

Department of Radiation Oncology, Shiraz University

of Medical Sciences, Shiraz, Iran

Y. Daneshbod

Department of Pathology, Dr. Daneshbod Pathology

Laboratory, Shiraz, Iran
[2]. These GCN may be encountered in 1 out of 500,000 live births [3]. Dermal nodules are considered benign in GCN that are present at birth, or which develop during childhood [3]. Skeletal developmental abnormalities have been reported to be associated with congenital nevi, especially GCN [4]. The risk of malignant change is probably the most contentious issue in their management. There is a consensus that GCN are pre-malignant, but the lifetime risk of this ominous transformation is purported to be $3.1 \%$ [5]. It is generally accepted that a complete excision in early childhood decreases the risk of malignancy. Another option (in cases with extensive dermal involvement) is a close monitoring by physical examination, including lymph node palpation and dermoscopy, with periodic follow-up and prompt excision if the lesion presents variations [6].

Conflict of interest The authors declare no conflict of interest.

\section{References}

1. Kopf AW, Bart RS, Hennessey P (1979) Congenital nevocytic nevi and malignant melanomas. J Am Acad Dermatol 1(2):123-130

2. Lanier VC Jr, Pickrell KL, Georgiade NG (1976) Congenital giant nevi: clinical and pathological considerations. Plast Reconstr Surg 58(1):48-54

3. van Houten AH, van Dijk MC, Schuttelaar ML (2010) Proliferative nodules in a giant congenital melanocytic nevus-case report and review of the literature. J Cutan Pathol 37(7):764-776

4. Tannous ZS et al (2005) Congenital melanocytic nevi: clinical and histopathologic features, risk of melanoma, and clinical management. J Am Acad Dermatol 52(2):197-203

5. Krengel S, Hauschild A, Schafer T (2006) Melanoma risk in congenital melanocytic naevi: a systematic review. Br J Dermatol 155(1):1-8

6. Surrenti T et al (2012) Melanoma in a 5-year-old child with a giant congenital melanocytic naevus. Acta Derm Venereol 92(6):607608 
Fig. 1 Giant, cobblestone, hairy congenital melanocytic nevus occupying the whole chest, upper abdomen, left arm, and neck with multiple satellite nevi scattered on other parts of body
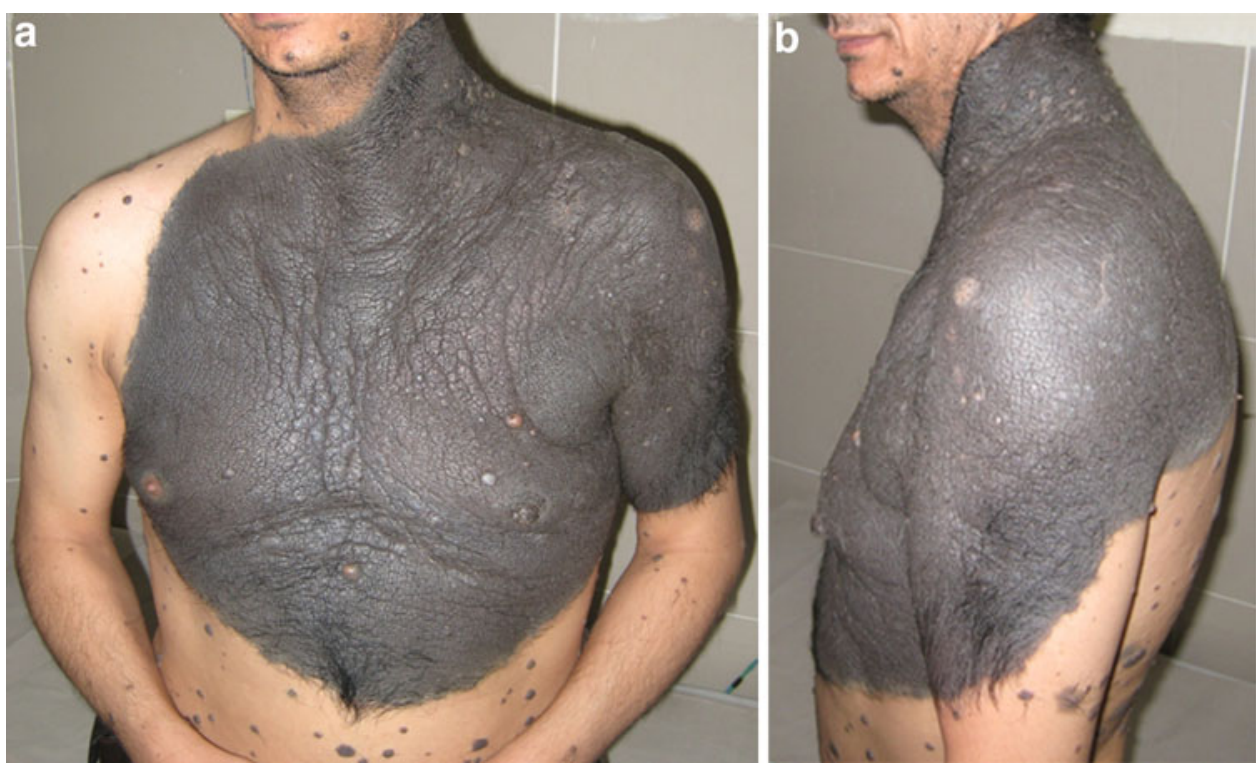